\title{
Possible dialogue between acupuncture, nursing and modulation of pain: assistance experience report
}

\author{
Mateus Casanova dos Santos \\ Department of Morphology, Biology Institut, School of Medicine, Federal University of Pelotas, Brazil \\ Correspondence: Mateus Casanova dos Santos. Address: Rua Av. Duque de Caxias, 250, Pelotas, Rio Grande do Sul, \\ Brazil. Telephone: 55-533-281-1326. E-mail: mateuscasanova@ig.com.br.
}

Received: May 31, 2012

DOI : $10.5430 /$ jnep.v3n3p88

Accepted: J une 24, 2012

URL: http://dx.doi.org/10.5430/jnep.v3n3p88

\section{Abstract}

This research involves discussions between the interfaces of scientific and nursing acupuncture in pain modulation through a case study with care qualitative and descriptive and participant of a patient under care and nursing. The aim is contextualize acupuncture in nursing as a potential supplement for pain control in actual clinical practice. It was concluded that the benefits of acupuncture in relation to pain modulation were conclusive to say that the optimization of the use of acupuncture in nursing consultation contributes to the efficacy in the treatment and functional rehabilitation. The analysis of this case study involving health care reported shoulder pain and the literature review, we find the need to promote scientific research to measure the benefits of acupuncture in musculoskeletal pain modulation.

\section{Key words}

Pain, Nursing, Acupuncture, Shoulder pain

\section{Introduction}

The pathophysiology of pain as feeling human species presents neural pathways and responses in organofunctional complex circuits. Among the many advances in science, the neuroscientific evidence, the studies on acupuncture and pain mechanisms denote sensory-discriminative, cognitive, behavioral, affective, motivational, autonomic and somatic added to known biochemical processes and neural control of pain ${ }^{[1-5]}$. The phenomenon is characterized as a nociceptive mechanism that includes the processes of transduction, conduction, transmission of nerve impulses and perceptions, resulting in nociceptive pain. In this regard, scientific knowledge of human nociceptive modulation and acupuncture add to the science of nursing care as a possibility for dialogue multidisciplinary, interdisciplinary and regulatory.

From the exciting story of experience involving the care chronic inflammatory pain ${ }^{[3]}$, presented the study aims to contextualize acupuncture in Nursing as a potential supplement in the control and nociceptive pain in actual clinical practice.

There are places in the human body skin of superficial meridians with high electrical conductivity: the acupoints. Qi as a vital force pervades the organic structures and visceral body ( $\mathrm{Zang} \mathrm{Fu}$ ) in various essential qualities. The connective tissue that intertwines the fluid mesh in different biochemical and electrical field is the interaction of nociceptive and pain. $Q i$ transitions, including physiological these spaces, carried neurochemical specific information. Acupuncture participates in 
the control of sensory, affective, behavioral and cognitive pain when excites receptors or nerve fibers in the tissues and produces rhythmic nerve discharges that release endogenous neurotransmitters, including oxytocin, enkephalins, pro-enkephalin, opioids, monoamines and other neuropeptides ${ }^{[3-10]}$.

Shoulder pain is a common health situation, in which up to one half of the population has at least one episode per year. In this sphere situational, tendinopathies of the rotator cuff are very common too. The requirements of the exercises are very promising and resolving, but there is little published research on quality and methodological sophistication ${ }^{[11,12]}$.

In this sense, the constitutional basis of acupuncture and scientific point of dialogue emerges as knowledge in clinical practice of health.

\section{I nterface methodology used}

The reporting of health care experience is a case study with a qualitative, descriptive and participant ${ }^{[13]}$ that integrates research entitled "Rescuing the full holistic care practices in complementary health", with approval by the Ethics Committee in Research of the Faculty of Medicine, Federal University of Pelotas, Office 009/05, 04/04/2005. The ethical research complied with Resolution 196/96 ${ }^{[14]}$. The observation period of the case study took place between the months of December 2008 and May 2011, in Porto Alegre, Brazil, using as a base customer service practices in complementary health.

To use the technique of acupuncture points were used as follows: Jianjing (VB21), Tianliao (TA15), Quyuan (ID13), Bingfeng (ID12), Tianzong (ID11), Jianz (ID9), Jianliao (TA14), Naohui (TA13), Binao (IG14), Jianyu (IG15), Zhongwan (VC12), Taibai (BP3), Zusanli (E36), Quchi (IG11), Tiaokou (E38), Shenmai (B62) e Houxi (ID3). Figure 1 helps to understand the use of acupuncture points with the clinical picture of the case.

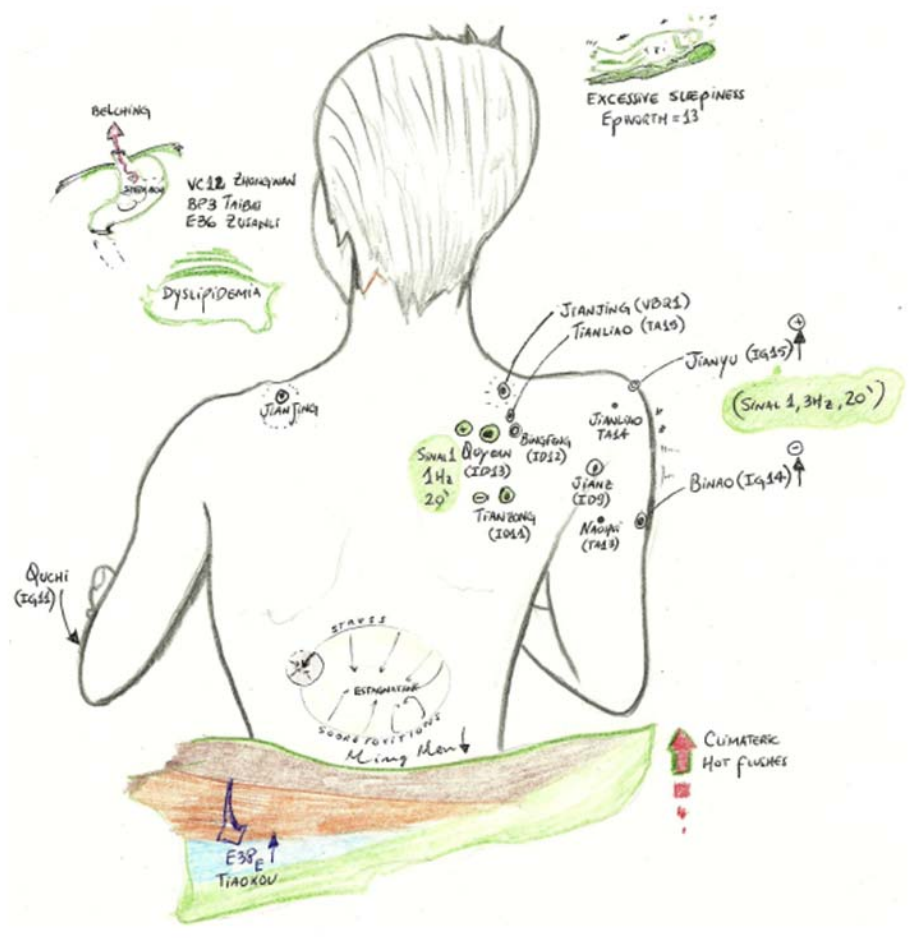

Figure 1. Anatomical and clinical clipboard developed to guide the archetypal image of the case history of shoulder pain with ideas and representations (source: author's research diary) 


\section{The Case Study: How Shoulder Pain Expression of A Pattern of Disability and Stagnation}

The patient called by its acronym T., 38 years old, single, female, Brazilian, teacher, height: 1.56 meters, body mass: $54000 \mathrm{~g}$, sought help of natural therapies in nursing on 12.12.2008, with consultation previously scheduled. In the consultation requested care chronic right shoulder pain. The patient was seen by an herbalist, physician and trauma medicine. During the clinical examination, the patient was in Glasgow fifteen; ambulating without assistance; lateral deviation to the right; blood pressure in the right arm systolic $110 \mathrm{mmHg}$ (millimeters of mercury) and $80 \mathrm{mmHg}$ diastolic; rhythmically symmetrical radial pulses at 60 beats per minutes, look slow, regular, superficial and thin $(\mathrm{Xi}){ }^{[6]}$, featuring Qi emptiness, weakness and moist diseases ${ }^{[5,6]}$, cognition and speech preserved; rosacea face, rosacea oral mucosa and full color, dry lips, tongue wide, tremulous, red on the tip and coating scarce; eupneic; eutérmica; continent and spontaneous diuresis, postprandial abdominal distension; eructos; bowel eliminations stable; preserved libido; limbs with adequate cutaneous integrity; no edemas, and , thermal symmetry in upper and lower limbs. Amenorrhea for twenty-four weeks and hot flashes. Restless sleep. The patient was under care for clinical pharmacological treatment of dyslipidemia, using orally ezetimibida 10mg and 20mg simvastatin daily. The examination indicated by ultrasound imaging features of the shoulder complex with morphological changes. The right upper limb and was suitable temperature; with pulses brachial, radial, ulnar and digital preserved; contour and preserved muscle mass, absence of deformity, joint stability gleno-umeral, acromioclavicular, esternoclavicular; scapulothoracic rhythm preserved; Spurling negative sign, and, Adson maneuver negative. On the right shoulder girdle had pain on palpation in acupoints Ig14 (Large Intestine 14) and Ig15, and on the anterolateral somatotopia upper limb. The patient had pain on abduction of the upper limb and difficulty in maintaining activities of daily living such as writing and elevate the limb anterior-posterior-laterally.

After clinical evaluation, identified as nursing diagnoses, based on Human Needs Theory and the North American Nursing Diagnosis Association ${ }^{[15]}$ : altered health maintenance, energy field disturbances, impaired social interaction, risk of neurovascular dysfunction peripheral risk of activity intolerance, fear, stress, anxiety, pain, hopelessness, low self-esteem situational potential deficit of self-care, disturbed sleep patterns, individual handling effective therapeutic regimen. In this sense, there was monitoring of the patient by a multidisciplinary group involving nurse, physician, herbalist and traumatologist support as coping with the disease. From the first two visits, we defined the diagnosis oriental classic, complementing the medical and nursing diagnoses. According to the eight principles: heat, vacuum, interior Yin; second six excesses: cold and damp; syndromic mixed: deficiency of Spleen Qi, Spleen blocked by humidity with Stagnation of Liver Qi, attack of external pathogenic factor cold and damp in the main channel Intestine (Da Chang), generating Yang Ming shoulder pain ${ }^{[5,6]}$. The complex of the shoulder joint receives Qi Gan (Liver) Qi and Shen (Kidneys). Electrophysiological changes of these organs can cause shoulder pains, especially chronic conditions ${ }^{[5,6,10]}$. It presents a complex picture with overlapping syndromic.

In a primary care, acupuncture is an effective treatment for a long time for patients with shoulder pain functional soft tissue injury ${ }^{[10]}$. For this purpose it was taken as the basis of reasoning therapeutic effective use of systemic acupuncture ${ }^{[3-6]}$, relying on the immediate pain control by toning empty (Shi), warming Yang, tonifying Qi, developing Yin, invigorating Qi and Defensive nutritional $Q i$ as well as expulsion from the cold dampness. During treatment, if toned-coupled Spleen, Kidney, Lung, dispersed the Liver and promoted coupled to the regulation and stimulation channels Bladder, Triple Warmer, Circulation, Sexuality, Governing Vessel, points Alarm at equidistant shoulder pain points and influence osteo-cartilaginous, blood and tendinomuscular channel ${ }^{[2-8]}$.

Starting on 12.12.2008, the program took place in twenty-four nursing visits on a monthly basis, making the last session of the series on 14.05.2011. The patient recovered completely shoulder pain improving right from the eighth meeting (11.14.2009), an improvement of abduction of the affected upper limb flares and the third meeting (14.02.2009), no stomach distension and abdominal distension from fourteenth meeting (22.05.2010), reducing the diversion of the right lateral ectoscopy from the twenty-first session (15.01.2011), and even softening the psychological conditions of fear, anxiety, stress, and presenting a positive response to face of pain and preservation of self-image. The indirect measurements of blood pressure of patients remained stable during the sessions. In the eighteenth query (02.10.2010), the 
patient had difficulty accepting the breakup of the relationship with the partner, which unfolded sadness and misrepresentation of Lung Qi (Fei). The patient remains in the monthly monitoring service in the treatment of dyslipidemia, disorders of sleep and rest and stress management psycho-affective.

The assessment of the constitutional pattern of the patient as weak and stagnant improved the symptomatic evaluation of nursing appointments, strengthening clinical and semiological principles to justify the nursing diagnoses listed interface and dialogue with the scientific practice of acupuncture.

The case indicates that the shoulder pain is not related to work (repetitive movements). This indicates a complexity to the clinical evaluation of the patient, involving the whole of health care. The symptomatic evaluation of the Eastern tradition in health contributed to rate this picture in full context.

In this case, was not the option for prescribing exercise as a method of treatment because it has identified increases in the levels of pain after exertion local muscle pressure in women with chronic shoulder pain ${ }^{[16]}$. This could affect the analysis of the study.

\section{Final considerations}

It is believed that this sphere of life sciences, nursing can dialogue with acupuncture for pain management care in different contexts. Pain as the fifth vital sign is capable of monitoring and even effective management by nursing through acupuncture. The sensitivity and capillary capacity of health services to this reality is the point of provoking discussion and requires further deepening and interdisciplinary dialogues in successive studies.

In a randomized controlled trial, the group of patients who underwent acupuncture had consistently better results in every secondary outcome than in the control group. In this sense, the practice of acupuncture was considered an effective long-term treatment for patients with shoulder pain in a primary care setting.

The therapeutic use of acupuncture needles through with the oriental art and science is a possibility and germinal intrinsic to the practice of nursing. The need for studies and advances in this area will be the driving force to help regulate this opportunity in order to contribute to the exercise of clinical practice of nursing ${ }^{[10]}$.

From the case presented, the benefits of acupuncture in controlling nociceptive been conclusive to say that optimization of the use of acupuncture in nursing consultation contributes to the effectiveness evaluation, treatment and functional rehabilitation. Still, it is considered that there is a need for further scientific studies to further the discussions between nursing, acupuncture and pain modulation. The analysis of this case study involving health care reported shoulder pain and the literature review, we find the need to promote scientific research to measure the benefits of acupuncture in musculoskeletal pain modulation.

Still, the diagnostic labels of shoulder pain are still widely used in international investigations and even in clinical practice, demonstrating the need to abolish the use of these expressions to describe clinical trials to come ${ }^{[17]}$. In this sense, the research was concerned to describe the disease entity based on Eastern tradition in health in order to improve evaluation. Although the study was limited by reporting a problem situation reveals the importance of the use of acupuncture in health practice everyday.

Some research motivated this case study. In a study of twenty-four women who worked in office and had shoulder pain associated with neck pain and headaches, proper acupuncture treatment has shown the potential to reduce chronic pain in the neck and shoulders and related headache and lasted by up to three years ${ }^{[18]}$. Walking this way, the Chinese acupuncture is considered a good alternative for the orthopedic treatment of chronic shoulder pain ${ }^{[19]}$. 
Although there is a hodgepodge of treatments for shoulder pain, especially in soft tissue injuries, such as intra-articular injections ${ }^{[20]}$, reparative surgeries, non-pharmacological measures are welcome at a level of initial attention. Based on the reported experience, acupuncture can help to care for pain modulation, preserving the individual's overall health, better coping with the disease and support interdisciplinary and multidisciplinary.

\section{References}

[1] Neto OA, Costa CM, Siqueira, JTT, Teixeira MJ. Dor: princípios e prática. Porto Alegre: Artmed. 2009. http://dx.doi.org/10.1016/S0140-6736(95)90066-7

[2] Ader R, Cohen N, Felten D. Psychoneuroimmunology: interactions between the nervous system and the immune system. The Lancet. 1995 Jan; 345(14): 99-103.

[3] Santos MC. Acupuntura no cuidado de enfermagem ao paciente com cisto pilonidal: um relato de experiência assistencial. Rev. Gaúcha Enferm. 2010; 31(1): 175-8. PMid:20839553 http://dx.doi.org/10.1590/S1983-14472010000100024

[4] Hsu DT. Acupuncture. Reg. Anest. 1996; 21: 361-70. PMid:8837198

[5] Maciocia G. Os fundamentos da Medicina Chinesa: um texto abrangente para acupunturistas e fitoterapeutas. São Paulo: Roca; 1996.

[6] Auteroche B, Navailh P. O diagnóstico na medicina chinesa. São Paulo: Andrei, 1992. PMid:1293608

[7] Leake R, Broderick JE. Treatment efficacy of acupuncture: a review of the research literature. Integrat. Med. 1998; 1(3): 107-115. http://dx.doi.org/10.1016/S1096-2190(98)00033-X

[8] Wang Y, Zhang Y, Wang W, Cao Y, Han J. Effects of synchronous or asynchronous eletroacupuncture stimulation with low versus high frequency on spinal opioid release and tail flick nociception. Exp. Neuro. 2005; 192: 156-162. PMid:15698629 http://dx.doi.org/10.1016/j.expneurol.2004.11.003

[9] Saku K, Mukaino Y, Ying H, Arakawa K. Characteristics of reactive electropermeable points on the auricles of coronary heart disease patients. Clin Cardiology. 1993; 16: 415-9. PMid:8504576 http://dx.doi.org/10.1002/clc.4960160509

[10] Hoyos JAG, Martín MCA, Leon EBB, Lopez MV, López TM, Morilla FAV, Moreno MJG. Randomised trial of long term effect of acupuncture for shoulder pain. Pain. 2004; 112: 289-98. PMid:15561384 http://dx.doi.org/10.1016/j.pain.2004.08.030

[11] Luime J, Koes B, Hendriksen I, Burdorf A, Verhagen A, Miedema H. Prevalence and incidence of shoulder pain in the general population: a systematic review. Scandinavian Journal of Rheumatology. 2004; 33(2): 73-81. PMid:15163107 http://dx.doi.org/10.1080/03009740310004667

[12] Littlewood C, Ashton J, Chance-Larsen K, May S, Sturrock B. Exercise for rotator cuff tendinopathy: a systematic review. Physiotherapy. 2012; 98: 101-109. PMid:22507359 http://dx.doi.org/10.1016/j.physio.2011.08.002

[13] Bogdan RC, Biklen SK. Investigação qualitativa em educação. Porto (Portugal): Porto; 1994.

[14] Ministério da Saúde (BR), Conselho Nacional de Saúde, Comitê Nacional de Ética em Pesquisa em Seres Humanos. Resolução 196, 10 out. 1996: diretrizes e normas regulamentadoras de pesquisa envolvendo seres humanos. Brasília (DF). 1996.

[15] Benedet AS, Bub MAC. Manual de diagnóstico de enfermagem: uma abordagem baseada na teoria das necessidades humanas básicas e na classificação diagnóstica da NANDA. Florianópolis: Bernúncia; 2001.

[16] Persson AL, Hansson G, Kalliomäki J, Sjölund B. Increases in local pressure pain thresholds after muscle exertion in women with chronic shoulder pain. Archives of Physical Medicine and Rehabilitation. 2003; 84(10): 1515-1522. http://dx.doi.org/10.1016/S0003-9993(03)00273-9

[17] Schellingerhout JM, Verhagen AP, Thomas S, Koes BW. Lack of uniformity in diagnostic labeling of shoulder pain: time for a different approach. Manual Therapy. 2008; 13(6): 478-483. PMid:18555732 http://dx.doi.org/10.1016/j.math.2008.04.005

[18] He D, Veiersted KB, Hostmark AT, Medbo JI. Effect of acupuncture treatment on chronic neck and shoulder pain in sedentary female workers: a 6-month and 3-year follow-up study. Pain. 2004; 109(3): 299-307. PMid:15157691 http://dx.doi.org/10.1016/j.pain.2004.01.018

[19] Molsberger AF, Schneider T, Gotthardt H, Drabik A. German Randomized Acupuncture Trial for chronic shoulder pain (GRASP) - a pragmatic controlled, patient-blinded, multi-centre trial in an outpatient care environment. Pain. 2010; 151(1): 146-154. PMid:20655660 http://dx.doi.org/10.1016/j.pain.2010.06.036

[20] Hegedus EJ, Zavala J, Kissenberth M, Cook C, Cassas K, Hawkins R, Tobola A. Positive outcomes with intra-articular glenohumeral injections are independent of accuracy. Journal of Shoulder and Elbow Surgery 2010; 19(6): 795-801. PMid:20655766 http://dx.doi.org/10.1016/j.jse.2010.03.014 